\title{
Metodologia Students' Evaluation of Teaching (SET): Potencialidades para a EaD
}

\author{
Thomaz Edson Veloso da Silva \\ Doutorando em Engenharia de Teleinformática e Ciências \\ (Universidade Federal do Ceará e Universidade de Copenhagen) \\ Coordenador de análise de dados, pesquisa e avaliação educacional da \\ Escola de Formação Permanente do Magistério e Gestão Educacional - Esfapege \\ $\triangle$ thomazveloso@virtual.ufc.br \\ Francisco Herbert Lima Vasconcelos \\ Professor Adjunto da Universidade Federal do Ceará \\ Secretário de Educação de Sobral - Ceará \\ $\square$ herbert@virtual.ufc.br
}

\section{Resumo:}

O atual cenário brasileiro continua apontando uma forte tendência: a utilização da EaD como facilitadora eminente dos processos de formações profissionais. No ano de 2016, o Centro de Educação a Distância do Ceará ofertou 32 cursos na modalidade EaD, capacitando mais de 4000 professores, gestores escolares e alunos, sendo que 2476 cursistas participaram voluntariamente desta pesquisa, avaliando o curso com base no instrumento de avaliação da qualidade do ensino QEOn, gerando os cinco indicadores. Este estudo aponta para uma das formas de utilização do QEOn para tomada de decisão por parte dos gestores do processo de formação via EaD.

Palavras-chave: Avaliação Educacional, Qualidade de Ensino, EaD.

\section{Students' Evaluation of Teaching (SET) Methodology: Possibilities on E-learning}

\begin{abstract}
:
The current Brazilian scenario continues to point to a strong trend: the use of e-learning as an eminent facilitator of professional training processes. In 2016, the Center for Distance Education in Ceará offered 32 courses via e-learning mode, training more than 4000 teachers, school administrators and students, and 2476 students participated voluntarily on this research, evaluating the course based on the evaluation of teaching quality instrument - QEOn, generating five indicators of quality. This study points to one of the ways in which the QEOn can be used for decision-making by the managers of the teaching and learning process via e-learning.

Keywords: Educational Assessment, Teaching Quality, E-learning.
\end{abstract}

\section{Metodología de Evaluación de la Enseñanza (SET): Posibilidades de E-learning}

\section{Resumen:}

El actual escenario brasileño sigue apuntando a una fuerte tendencia: la utilización de la EaD como facilitadora eminente de los procesos de formaciones profesionales. En el año 2016, el Centro de 
Educación a Distancia de Ceará ofreció 32 cursos en la modalidad EaD, capacitando a más de 4000 profesores, gestores escolares y alumnos, siendo que 2476 cursistas participaron voluntariamente de esta investigación, evaluando el curso con base en el instrumento de evaluación de la evaluación de la calidad de la enseñanza - OEOn, generando los cinco indicadores. Este estudio apunta a una de las formas de utilización del QEOn para la toma de decisión por parte de los gestores del proceso de formación vía EaD.

Palabras clave: Evaluación Educativa, Calidad de la Enseñanza, EaD.

\section{INTRODUÇÃO}

O embasamento teórico do pioneirismo da Educação a Distância (EaD) no mundo é escasso. A EaD está baseada no simples fato do ensino e a aprendizagem ocorrerem sem a necessidade do professor e o aluno estarem presencialmente em um mesmo espaço físico.

As gerações da EaD perpassam pela comunicação através de cartas, transmissão de rádio, aulas na TV e a utilização da internet (ALVES, 2011). As gerações estão inteiramente ligadas ao meio de comunicação utilizado para transmitir um determinado conteúdo. Os anos passaram, mas os moldes vistos atualmente na EaD são decorrentes de um processo elaborado que vem sendo trabalhado desde os seus primórdios. Vale ressaltar que, juntamente com a evolução das tecnologias digitais de informação e comunicação, precisam evoluir também as metodologias de aplicação e condução de cursos, além de materiais didáticos específicos.

$O$ atual cenário brasileiro continua apontando uma forte tendência: a utilização da $\mathrm{EaD}$ como facilitadora eminente dos processos de formações profissionais, tanto como suporte da modalidade presencial, quanto na semipresencial. O grau de utilização da EaD depende da natureza dos cursos, seus conteúdos e da possibilidade do emprego de uma metodologia adequada para sua utilização.

Em 1998, a extinta Secretaria de Educação a Distância (SEED) do Ministério da Educação (MEC), elaborou um ensaio sobre os padrões de qualidade para os cursos ofertados na modalidade EaD, o qual tornou-se referência para as instituições que ofertariam cursos de graduação a distância. A versão mais atual desse documento data do ano de 2007, que continua norteando os padrões de qualidade dos cursos em EaD no Brasil (SEED, 2007).

Para garantir a qualidade dos cursos em EaD, e devido à complexidade e à necessidade de uma abordagem sistemática, indicadores de qualidade de cursos em EaD 
devem compreender categorias que envolvem, fundamentalmente, aspectos pedagógicos, recursos humanos e infraestrutura. Tendo como principais tópicos (SEED, 2007): Concepção de educação e currículo no processo de ensino e aprendizagem; Sistemas de Comunicação; Material didático; Avaliação; Equipe multidisciplinar; Infraestrutura de apoio; Gestão Acadêmico-Administrativa; Sustentabilidade financeira.

Embora tenha ocorrido uma expansão na oferta de cursos a distância no Brasil, uma preocupação constante das Instituições de Ensino Superior (IES) é a respeito da qualidade dos cursos que são oferecidos. Tal preocupação torna fundamental a pesquisa e verificação da qualidade dos cursos de formação utilizando a modalidade EaD.

A importância de se avaliar recai, principalmente, na melhoria da qualidade da educação. No entanto, este objetivo causa controvérsia pois, ao invés de servir de base para intervenções pedagógicas, a avaliação educacional pouco tem tido propósito. Tais aspectos são discutidos detalhadamente em Sobrinho (2000) e Peixoto (2004).

Este trabalho tem como objetivo apresentar a metodologia Students' Evaluation of Teaching (SET) para avaliação da qualidade do ensino na modalidade EaD a partir da sua aplicação em ambiente real. O SET tem como princípio uma avaliação realizada pelos alunos sobre assertivas que compõe indicadores de qualidade do ensino, conforme apresentado em Marsh e Bailey (1993) e validado para o contexto brasileiro da EaD por Silva et al. (2017). A adequação da metodologia SET para EaD, e seus possíveis ganhos para melhoria da qualidade do ensino, serão apresentadas e exemplificadas, incluindo também a possibilidade de discussão da diminuição de uma problemática constante nessa modalidade de ensino: a evasão.

\section{AVALIAÇ̃̃o EDUCACIONAL}

A avaliação, em seu sentido amplo, pode ser definida como um processo que procura analisar informações que possibilitem uma melhor tomada de decisão por parte de quem está gerenciando o processo avaliado, e ainda mais, ela deve ser compreendida como um conjunto de atividades que procurem coletar um grande número de diferentes tipos de informação que otimizem essa tomada de decisão. 
Avaliar perpassa por vários fatores, que tão somente a aprendizagem discente, a busca por respostas que potencializem o esforço de gestores, docentes e discentes pela educação de qualidade não ultrapassa a compreensão da sua complexa realidade. Certamente por isso as investigações sobre avaliação ganham cada vez mais espaço na pesquisa científica.

Embora muitas pessoas associem o termo avaliação com o termo mensuração, até mesmo nos dias atuais, no qual o ato de se avaliar consiste em atribuir uma nota, a medida pode ser um momento inicial da avaliação, mas não é condição essencial para que se tenha avaliação (VIANNA, 2000).

Seguindo a mesma tendência, a avaliação está atrelada a atribuição de valor de alguma coisa para determinada finalidade, ou seja, pode-se tratar de um programa, um produto e não necessariamente apenas do rendimento escolar, ou o que muitos chamam de avaliação da aprendizagem (VIANNA, 2000). A avaliação procura sistematizar suas atividades para, aos poucos, criar uma complexa teia de coleta de diferentes tipos de informações que possibilitem um juízo de valor sobre o que está sendo avaliado, possibilitando a tomada de decisões face ao que foi encontrado.

Segundo Tyler (1993) a educação é um processo que visa a criar padrões de conduta, ou modificar padrões anteriores, nos indivíduos. Ainda nesta perspectiva, entende-se padrões de conduta como os objetivos educacionais a serem alcançados ao final de um processo avaliativo. Sendo o sucesso do programa atribuído ao atingimento desses objetivos pré-estabelecidos. Ainda segundo Tyler (1993), a avaliação deve ter caráter global, levando em consideração o conhecimento, habilidades, modo de pensar, atitudes e interesses dos alunos, a qual não deve ser centrada no aluno, como um ato isolado, mas um trabalho solidário que deve envolver alunos, professores, administradores e pais.

Com base nos pressupostos de Tyler, uma avaliação justa perpassa pelo desenvolvimento de diversas formas de avaliar, procurando atingir os objetivos educacionais propostos. No caso das IES, um dos objetivos educacionais almejados é a formação humana de qualidade. 


\section{METODOLOGIA STUDENTS' EVALUATION OF TEACHING}

A metodologia Students' Evaluation of Teaching (SET) foi desenvolvida pelo Prof. Herbert M. Marsh, a qual é comumente utilizada em todo o mundo (MARSH e HOCEVAR, 1991A; MARSH e HOCEVAR, 1991B; MARSH e BAILEY 1993; MARSH e ROCHE, 1997). O SET tem como principais propósitos:

- Dar aos professores um feedback diagnóstico sobre a efetividade do que eles estão ensinando;

- Medir a efetividade do ensino a partir de indicadores de qualidade para decisões pessoais;

- Subsidiar os alunos na escolha das disciplinas que serão cursadas; e

- Apresentar resultados que possibilitem pesquisas para melhoria do ensino e aprendizagem.

A metodologia SET é toda baseada no desenvolvimento de instrumentos de avaliação que levem em consideração a opinião (feedback) dos alunos. Marsh e Roche (1997) defendem que: Quem pode melhor avaliar o professor do que seus próprios alunos? o feedback dado pelos alunos costuma ser dado através de um grau de concordância dele com uma determinada assertiva, como forma mais tradicional de coletar esse grau, temos a escala Likert. Neste processo, torna-se importante que, com os resultados obtidos, relatórios sejam desenvolvidos e apresentados aos professores e/ou gestores educacionais, a fim de possibilitar possíveis tomadas de decisão que melhorem o processo de ensino e aprendizagem do aluno.

Pesquisadores concordam que o ensino é uma atividade complexa que consiste em múltiplas dimensões e que as avaliações formativas e diagnósticas precisam levar em consideração essa multidimensionalidade (MARSH e BAILEY, 1993; SPOOREN e MORTELMANS, 2006; OZKAN e KOSELER, 2009). Esta necessidade está suportada pelo senso comum e por inúmeras pesquisas empíricas.

Avaliações em geral não representam adequadamente a multidimensionalidade do ensino, tornando-as suscetíveis ao contexto de implementação do instrumento, o modo de aplicação e aspectos muito específicos. 


\section{Como avaliar utilizando a metodologia SET?}

Em muitas instituições, os instrumentos de avaliação, levando em consideração o feedback do aluno, não asseguram a validade do instrumento, tendo em vista que eles não passaram pelos rigorosos procedimentos de validação propostos pela psicometria (RICHARDSON, 2005a). Esses procedimentos procuram responder uma pergunta simples: "O instrumento de avaliação realmente avalia aquilo que ele se propõe a avaliar?".

Um passo muito importante para a implementação da metodologia SET é a sensibilização dos estudantes para a importância da avaliação. Esse procedimento se torna fundamental para um diagnóstico fidedigno do processo, fazendo com que a avaliação seja mais fiel à realidade do estudante. Alguns pontos tornam-se essenciais a serem esclarecidos quando da aplicação da metodologia SET: Conscientizar os estudantes que as respostas da avaliação serão utilizadas; as avaliações são aplicadas na última semana de aula; Pessoas desconhecidas pelos estudantes devem aplicar a avaliação; As instruções de participação do estudante devem estar claras e objetivas.

Embora alguns pesquisadores questionem a capacidade dos alunos em avaliar os docentes, ficou constatado que as respostas dadas pelos alunos são válidas e merecem ser levados em consideração para a tomada de decisão por parte dos professores ou gestores do processo educacional (RICHARDSON, 2005a; SPOOREN e MORTELMANS, 2006; YUEH et al., 2012).

\section{O instrumento QEOn}

Os instrumentos do SET são desenvolvidos para medir separadamente os componentes do ensino e a validade do construto para múltiplas dimensões também precisa ser verificada. Com base nisso, dois instrumentos se destacam como sendo base para a utilização da metodologia SET pelo mundo na modalidade presencial, Students' Evaluation of Educational Quality (SEEQ) e o Course Experience Questionnaire (CEQ) (RICHARDSON, 2005a), e, mais recentemente, o instrumento Qualidade de Ensino Online (QEOn) foi validado para o contexto da EaD (SILVA et al., 2017) além de outros encontrados em (RICHARDSON, 2005b). 
Tabela 1 - Questionário QEOn.

\begin{tabular}{|c|c|c|c|c|c|c|c|c|c|c|c|}
\hline & Assertivas & $\begin{array}{r}\text { Dis } \\
\text { Forte }\end{array}$ & $\begin{array}{ll}\text { ordo } \\
\text { mente } \\
\end{array}$ & $\begin{array}{r}\text { Disc } \\
\text { Parcia } \\
\end{array}$ & $\begin{array}{ll}\text { rrdo } \\
\text { mente }\end{array}$ & $\begin{array}{r}\text { Indife } \\
\mathrm{e}\end{array}$ & erent & $\begin{array}{r}\text { Conc } \\
\text { Parcial } \\
\end{array}$ & $\begin{array}{ll}\text { cordo } \\
\text { Imente } \\
\end{array}$ & $\begin{aligned} \text { Conc } \\
\text { Forte }\end{aligned}$ & $\begin{array}{ll}\text { icordo } \\
\text { emente }\end{array}$ \\
\hline Q1 & $\begin{array}{l}\text { Você considera o curso intelectualmente } \\
\text { desafiador e estimulante. }\end{array}$ & ( & ) & ( & ) & ( & ) & ( & ) & ( & ) \\
\hline Q2 & Você aprendeu algo que considera pertinente. & ( & ) & ( & ) & ( & ) & ( & ) & ( & ) \\
\hline Q3 & $\begin{array}{l}\text { O seu interesse sobre o tema cresceu como } \\
\text { consequência do curso. }\end{array}$ & ( & ) & ( & ) & ( & ) & ( & ) & ( & ) \\
\hline Q4 & Você compreendeu os conteúdos do curso. & ( & ) & ( & ) & ( & ) & ( & ) & ( & ) \\
\hline Q10 & $\begin{array}{l}\text { Os materiais do curso foram bem preparados e } \\
\text { cuidadosamente transmitidos. }\end{array}$ & ( & ) & ( & ) & ( & ) & ( & ) & ( & ) \\
\hline Q11 & $\begin{array}{l}\text { Os objetivos propostos estão de acordo com o } \\
\text { que foi ensinado durante o curso. }\end{array}$ & ( & ) & ( & ) & ( & ) & ( & ) & ( & ) \\
\hline Q5 & $\begin{array}{l}\text { O tutor à distância mostrou entusiasmo ao } \\
\text { ministrar o curso. }\end{array}$ & ( & ) & ( & ) & ( & ) & ( & ) & ( & ) \\
\hline Q6 & $\begin{array}{l}\text { O tutor à distância foi dinâmico e energético na } \\
\text { condução do curso. }\end{array}$ & ( & ) & ( & ) & ( & ) & ( & ) & ( & ) \\
\hline Q7 & $\begin{array}{l}\text { O tutor à distância melhora a apresentação dos } \\
\text { conteúdos com sugestões de sites e vídeos. }\end{array}$ & ( & ) & ( & ) & ( & ) & ( & ) & ( & ) \\
\hline Q8 & $\begin{array}{l}0 \text { tutor à distância apresenta interesse pelo } \\
\text { aprendizado do aluno. }\end{array}$ & ( & ) & ( & ) & ( & ) & ( & ) & ( & ) \\
\hline Q9 & O tutor à distância elucida as indagações. & ( & ) & ( & ) & ( & ) & ( & ) & ( & ) \\
\hline Q12 & $\begin{array}{l}\text { O tutor à distância propôs leituras } \\
\text { complementares que facilitam a obtenção de } \\
\text { nota. }\end{array}$ & ( & ) & ( & ) & ( & ) & ( & ) & ( & ) \\
\hline Q21 & $\begin{array}{l}\text { O tutor à distância relaciona as implicações do } \\
\text { conteúdo com várias teorias. }\end{array}$ & ( & ) & ( & ) & ( & ) & ( & ) & ( & ) \\
\hline Q22 & $\begin{array}{l}\text { O tutor à distância apresenta fundamentos } \\
\text { preliminares de ideias/concepções que são } \\
\text { desenvolvidas nas atividades virtuais. }\end{array}$ & ( & ) & ( & ) & ( & ) & ( & ) & ( & ) \\
\hline Q23 & $\begin{array}{l}\text { O tutor à distância apresenta seu ponto de vista } \\
\text { quando julga adequado. }\end{array}$ & ( & ) & ( & ) & ( & ) & ( & ) & ( & ) \\
\hline Q24 & $\begin{array}{l}\text { O tutor à distância comenta adequadamente as } \\
\text { pesquisas atuais desenvolvidas na área de } \\
\text { estudo. }\end{array}$ & ( & ) & ( & ) & ( & ) & ( & ) & ( & ) \\
\hline Q13 & $\begin{array}{l}\text { Os cursistas são encorajados a participarem das } \\
\text { discussões no fórum. }\end{array}$ & ( & ) & ( & ) & ( & ) & ( & ) & ( & ) \\
\hline Q14 & $\begin{array}{l}\text { Os cursistas são convidados a compartilhar suas } \\
\text { ideias e conhecimentos. }\end{array}$ & ( & ) & ( & ) & ( & ) & ( & ) & ( & ) \\
\hline Q15 & $\begin{array}{l}\text { Os cursistas são encorajados a responder a } \\
\text { questão central do fórum. }\end{array}$ & ( & ) & ( & ) & ( & ) & ( & ) & ( & ) \\
\hline Q16 & $\begin{array}{l}\text { Os cursistas são estimulados pelo tutor a } \\
\text { distância a propor ideias/questionamentos } \\
\text { transversais ao tema central do fórum. }\end{array}$ & ( & ) & ( & ) & ( & ) & ( & ) & ( & ) \\
\hline Q17 & $\begin{array}{l}\text { O tutor presencial foi amigável na relação com } \\
\text { os cursistas. }\end{array}$ & ( & ) & ( & ) & ( & ) & ( & ) & ( & ) \\
\hline Q18 & $\begin{array}{l}\text { O tutor presencial fez com que os cursistas se } \\
\text { sintam confortáveis com sua ajuda no polo de } \\
\text { atendimento. }\end{array}$ & ( & ) & ( & ) & ( & ) & ( & ) & ( & ) \\
\hline Q19 & $\begin{array}{l}\text { O tutor presencial tem interesse genuíno em } \\
\text { relação ao aprendizado do cursista. }\end{array}$ & ( & ) & ( & ) & ( & ) & ( & ) & ( & ) \\
\hline Q20 & $\begin{array}{l}\text { O tutor presencial se mostra disponível no } \\
\text { horário de atendimento no polo. }\end{array}$ & ( & ) & ( & ) & ( & ) & ( & ) & ( & ) \\
\hline Q25 & $\begin{array}{l}\text { Há a disponibilidade das correções das } \\
\text { avaliações/trabalhos de forma adequada. }\end{array}$ & ( & ) & ( & ) & ( & ) & ( & ) & ( & ) \\
\hline Q26 & $\begin{array}{l}\text { Os métodos de avaliação do cursista são justos e } \\
\text { apropriados ao curso. }\end{array}$ & ( & ) & ( & ) & ( & ) & ( & ) & ( & ) \\
\hline Q27 & $\begin{array}{l}\text { As avaliações/materiais para os testes são } \\
\text { trabalhados pelo tutor à distância. }\end{array}$ & ( & ) & ( & ) & ( & ) & ( & ) & ( & ) \\
\hline Q28 & $\begin{array}{l}\text { O curso requer a leitura de textos que estão } \\
\text { disponíveis. }\end{array}$ & ( & ) & ( & ) & ( & ) & ( & ) & ( & ) \\
\hline Q29 & $\begin{array}{l}\text { Leituras complementares, chat, fóruns, } \\
\text { portfólios contribuem para apreciação e } \\
\text { compreensão dos conteúdos. }\end{array}$ & ( & & ( & ) & ( & ) & ( & ) & ( & ) \\
\hline
\end{tabular}

Fonte: (SILVA et al, 2017). 
Para a validação dos instrumentos, uma técnica da estatística multivariada chamada Análise Fatorial foi aplicada a fim de classificar as assertivas presentes no construto. Testes e verificações estatísticas são realizadas a fim de garantir a aplicabilidade da Análise Fatorial na base de dados coletada, bem como medem a confiabilidade das medidas realizadas, para esse fim, destacamos o coeficiente de confiabilidade alpha de Cronbach e os testes KMO de adequação da amostra e de esfericidade de Bartllet (SILVA et al., 2017). Pode-se concluir que os instrumentos são:

- Multidimensionais;

- Estáveis e confiáveis;

- Válidos em relação a variedade de indicadores de efetividade do ensino.

O Instrumento QEOn, desenvolvido por Silva et al. (2017), apresenta em sua configuração inicial cinco fatores/indicadores sobre a qualidade de cursos a distância no qual os participantes da avaliação darão seu grau de concordância com a assertiva a partir de uma escala Likert de cinco pontos (ver Tabela 1). Na Tabela 2 estão apresentados os fatores do QEOn adaptados à realidade do ensino a distância promovido pela Universidade Aberta do Brasil (UAB), sendo caracterizado por fatores relacionados ao Tutor presencial e online, ao aluno e ao curso. 0 instrumento contém 29 assertivas.

Tabela 2 - Fatores QEOn e suas descrições.

\begin{tabular}{|c|l|}
\hline Fatores QEOn & \multicolumn{1}{|c|}{ Descrição do Fator } \\
\hline Aprendizagem & $\begin{array}{l}\text { O aluno avalia a sua aprendizagem quanto ao conteúdo } \\
\text { programático do curso }\end{array}$ \\
\hline Perfil Tutor Online & $\begin{array}{l}\text { O Tutor online demostra dinamismo, entusiasmo e interesse no } \\
\text { aprendizado do aluno e teve o cuidado de preparar as aulas } \\
\text { virtuais em uma organização sistemática de suas ideias. }\end{array}$ \\
\hline $\begin{array}{c}\text { Interação Tutor } \\
\text { Online/Cursista }\end{array}$ & $\begin{array}{l}\text { Está associado à capacidade do Tutor online resgatar a atenção da } \\
\text { turma, aprimorando a discussão dos conteúdos. }\end{array}$ \\
\hline $\begin{array}{c}\text { Relação Tutor } \\
\text { Presencial/Cursista }\end{array}$ & $\begin{array}{l}\text { Apresenta se o Tutor Presencial estava sempre atento e disposto } \\
\text { a resolver os problemas apresentados pelos alunos. }\end{array}$ \\
\hline Processos & $\begin{array}{l}\text { Está associado ao fato dos processos avaliativos terem sido } \\
\text { coerentes e esclarecidos ao longo do curso e relaciona as } \\
\text { atividades/trabalhos do curso com a realidade do conteúdo } \\
\text { apresentado, bem como sua aplicabilidade no contexto dos } \\
\text { alunos }\end{array}$ \\
\hline
\end{tabular}

Fonte: Os autores. 


\section{METODOLOGIA DA PESQUISA}

Uma revisão da literatura é feita em Apressola (2010), a qual apresenta vários modelos de instrumento de avaliação de tutores no Brasil, entretanto a autora aponta alguns problemas nos instrumentos avaliados: "os modelos são muito ligados a uma só instituição" dificultando sua replicação em outras IES; falta clareza nos indicadores propostos; não há nenhuma preocupação quanto ao rigor da validação do instrumento. Para sanar tais problemas, Apressola (2010) apresenta a validação de um instrumento de avaliação de tutores com todo o rigor e sentido exigidos pela psicometria.

Mais abrangente do que o instrumento proposto em Apressola (2010), o instrumento QEOn apresenta a possibilidade de avaliar além dos tutores, os alunos e o curso ao qual estão vinculados. O suporte analítico fatorial dado por esses instrumentos garante sua aplicabilidade e confiabilidade no contexto da EaD.

\section{Contexto de aplicação da pesquisa}

O Centro de Educação a Distância do Estado do Ceará - CED é um equipamento da Secretaria de Educação do Ceará e é responsável pela prestação de diversos serviços relacionados à organização e à realização de cursos de formação profissional, dentre eles, encontram-se os cursos de formação básica e continuada para professores da rede pública do Estado do Ceará. Sua missão social e institucional se cumpre junto à sociedade na medida em que tais cursos são desenvolvidos e ofertados para públicos alvos específicos, sendo sempre coerentes com o avanço das tecnologias e metodologias que acompanham as transformações educacionais e profissionais.

No ano de 2016, 32 cursos na modalidade EaD foram ofertados à comunidade, capacitando mais de 4000 professores, gestores escolares e alunos. Todo público foi convidado voluntariamente a avaliar seus respectivos cursos. Dessa forma, 2476 cursistas participaram da pesquisa, avaliando o curso com base no QEOn e gerando os cinco indicadores de qualidade do ensino. 


\section{RESULTADOS OBTIDOS: POTENCIALIDADES PARA A EAD NO BRASIL}

Com a aplicação do QEOn, foram obtidos cinco indicadores de qualidade do ensino para cada um dos 32 cursos avaliados. Tais resultados estão apresentados e discutidos a seguir.

Na Figura 1, temos os resultados obtidos por cada curso em relação ao fator Aprendizagem. Pode-se observar que, os cursos Fundamentos em Redes de Computadores, Design Gráfico Básico, Formação para Planetaristas e Produção e Montagem Audiovisual, tiveram pontuações bem inferiores quando comparadas à media geral. Tal resultado indica que, na opinião discente, a aprendizagem do conhecimento passado não foi eficaz.

Figura 1 - Gráfico do fator Aprendizagem.

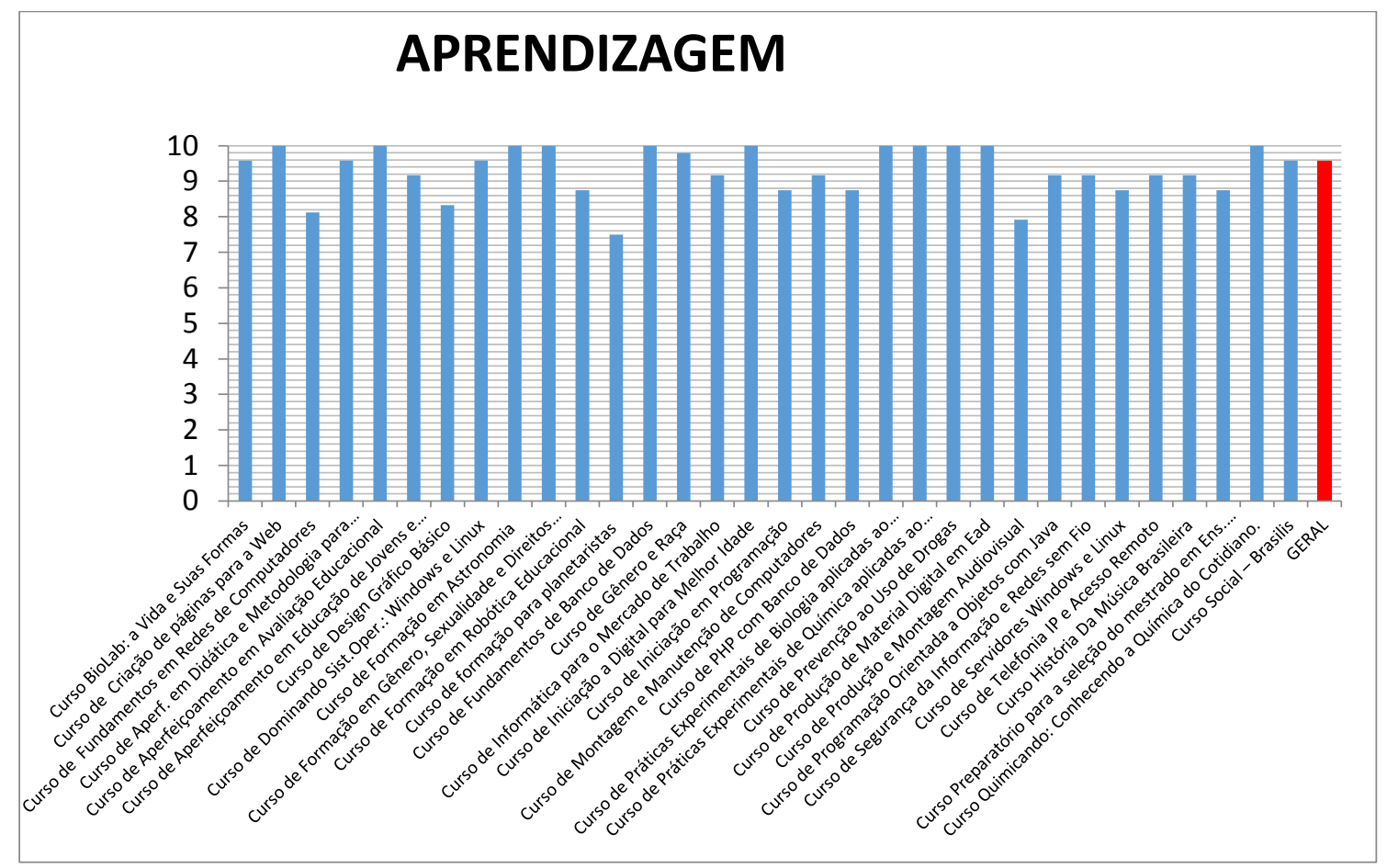

Fonte: Os autores.

Em relação ao que se apresenta na Figura 2, parte dos cursos que obtiveram baixo índice no fator Aprendizagem também apresentam deficiência no fator Perfil Tutor Online. Tal resultado precisa ser melhor analisado, tendo em vista que a atuação e o perfil do tutor online são preponderantes para o sucesso do curso, inclusive diminuindo suas taxas de evasão. Além dessa constatação, cursos com caráter mais técnicos tiveram também um 
índice baixo, indicando que uma formação precisa ser ofertada a esses tutores, para que melhorem sua prática pedagógica virtual.

Figura 2 - Gráfico do fator Perfil Tutor Online.

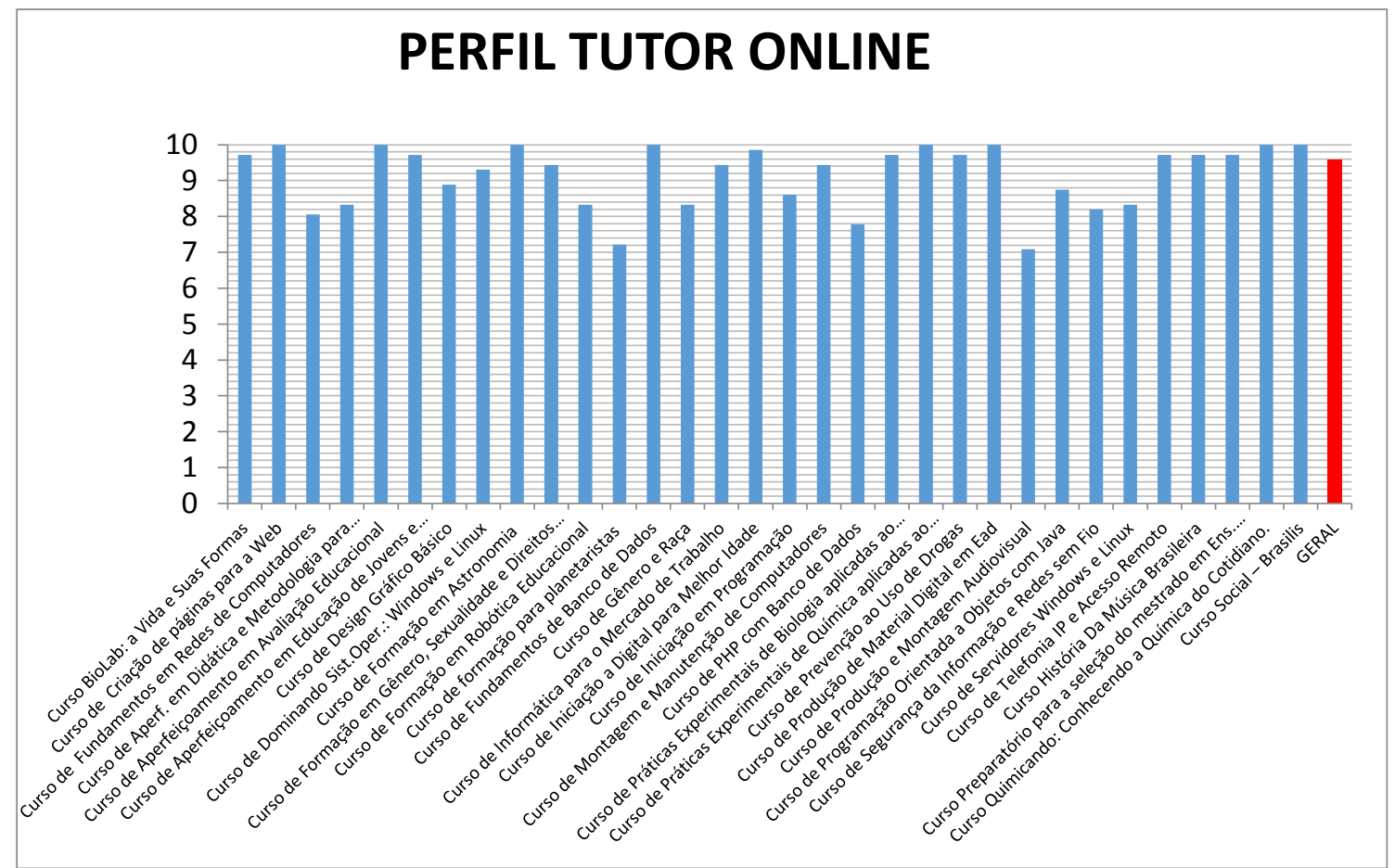

Fonte: Os autores.

Tal como apresenta a Figura 2, a Figura 3 está diretamente ligada a pessoa do tutor online, deixando claro que o fator Interação Tutor Online/Cursista é a principal forma de comunicação entre quem está no curso e quem está gerenciando as atividades pedagógicas. Se a comunicação entre os agentes do curso não acontece, fatalmente o nível de aprendizagem também decai (RIBEIRO et al., 2013).

Na estrutura oferecida pelo CED, existia a figura do tutor presencial que era um profissional de uma área mais genérica que tinha horário fixo no CED para receber alunos com dúvidas ou outras necessidades. Sendo assim, na Figura 4, apresentamos a medida dessa interação e percebe-se que nos cursos de Formação de Planetaristas e de Produção e Montagem Audiovisual tiveram os menores índices para esse fator em relação aos cursos em geral. Há uma manutenção da premissa de que cursos mais técnicos acarretam maior dificuldade de interação tanto por parte do tutor presencial quanto pelo tutor online. 
Figura 3 - Gráfico do fator Interação Tutor Online/Cursista.

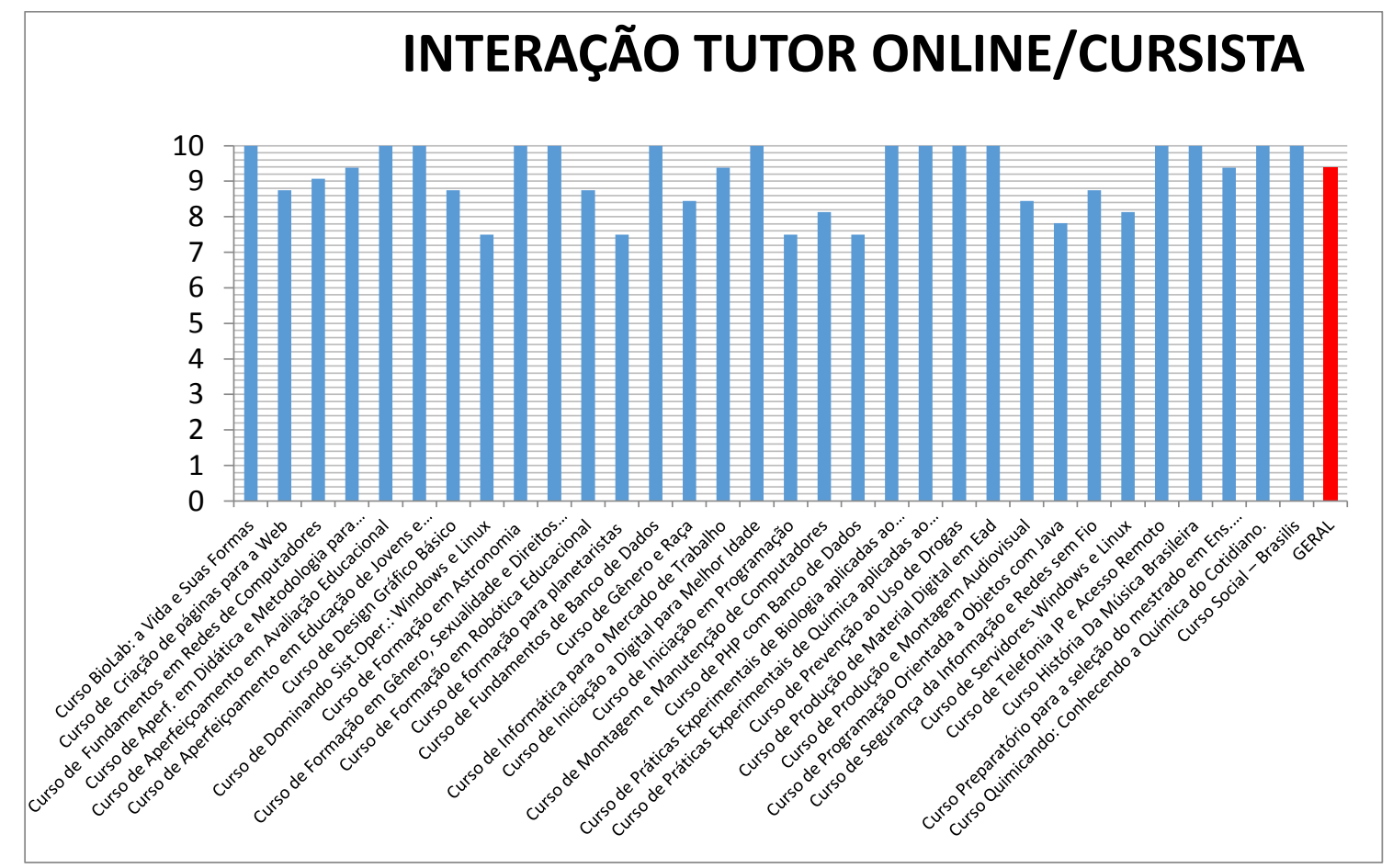

Fonte: Os autores.

Havia uma flexibilização dos processos avaliativos dos cursos quanto a sua natureza. As avaliações poderiam ser feitas por atividades presentes no AVA, pela entrega de um produto ou pela análise de uma prova prática no dia do último encontro presencial. Sendo assim, nenhuma comparação entre o modelo de avaliação pode ser feita, mas há que se analisar que alguns cursos precisam aprimorar seus processos avaliativos, como pode ser observado na Figura 5.

De acordo com Abbad (2010), a permanência ou evasão do aluno na EaD depende: do compromisso dos alunos em concluir o curso; do comprometimento do aluno com suas obrigações externas ao âmbito acadêmico; da sua formação escolar anterior; da sua integração acadêmica; e da integração social do aluno. Os últimos dois fatores de permanência e evasão aparecem como indicadores no instrumento QEOn, o que permite, depois de aplicações sistemáticas, a verificação de fatores que influenciam a evasão escolar, podendo essa ser combatida pelos gestores educacionais. 
Figura 4 - Gráfico do fator Relação Tutor Presencial/Cursista.

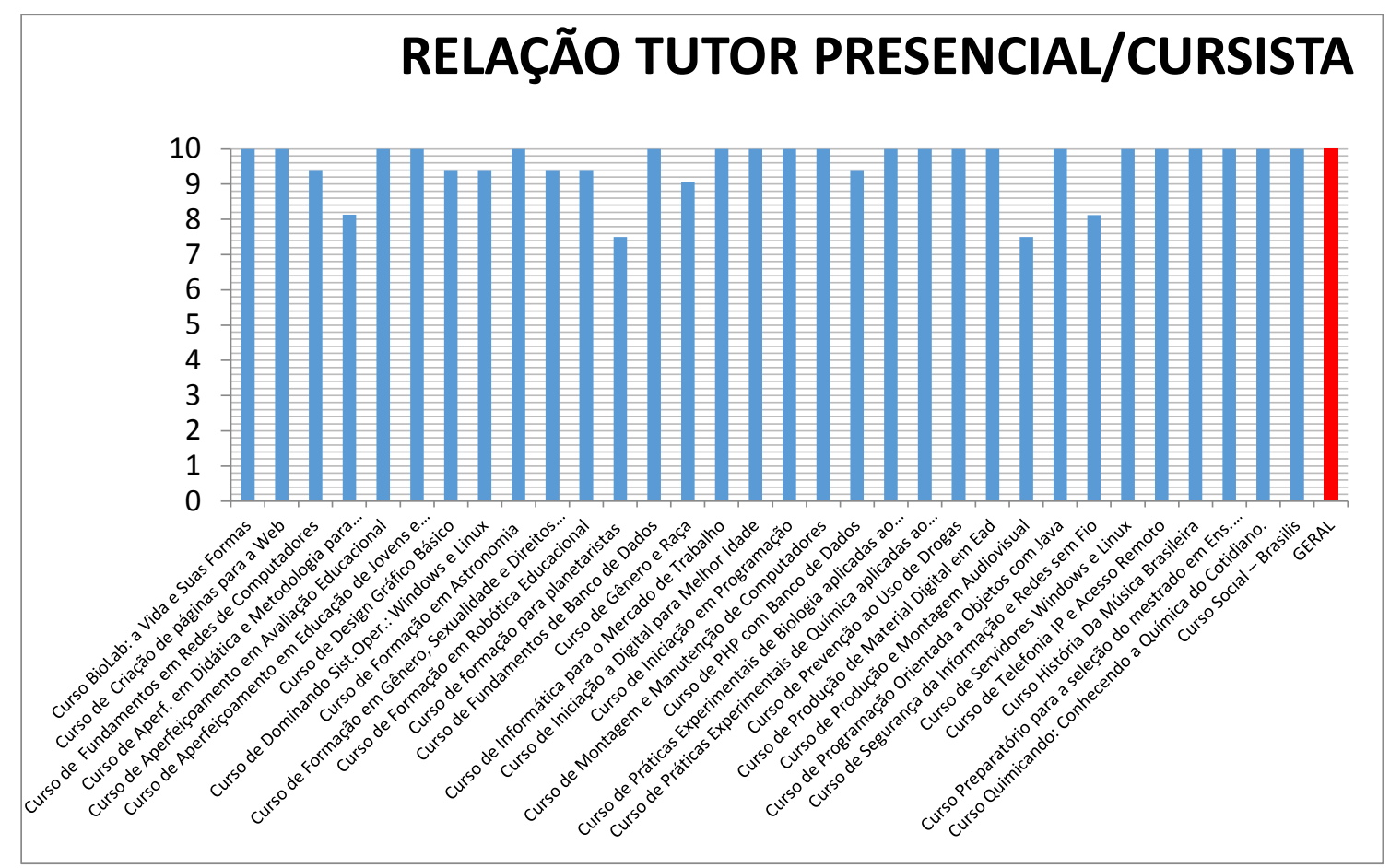

Fonte: Os autores.

Figura 5 - Gráfico do fator Processos Avaliativos

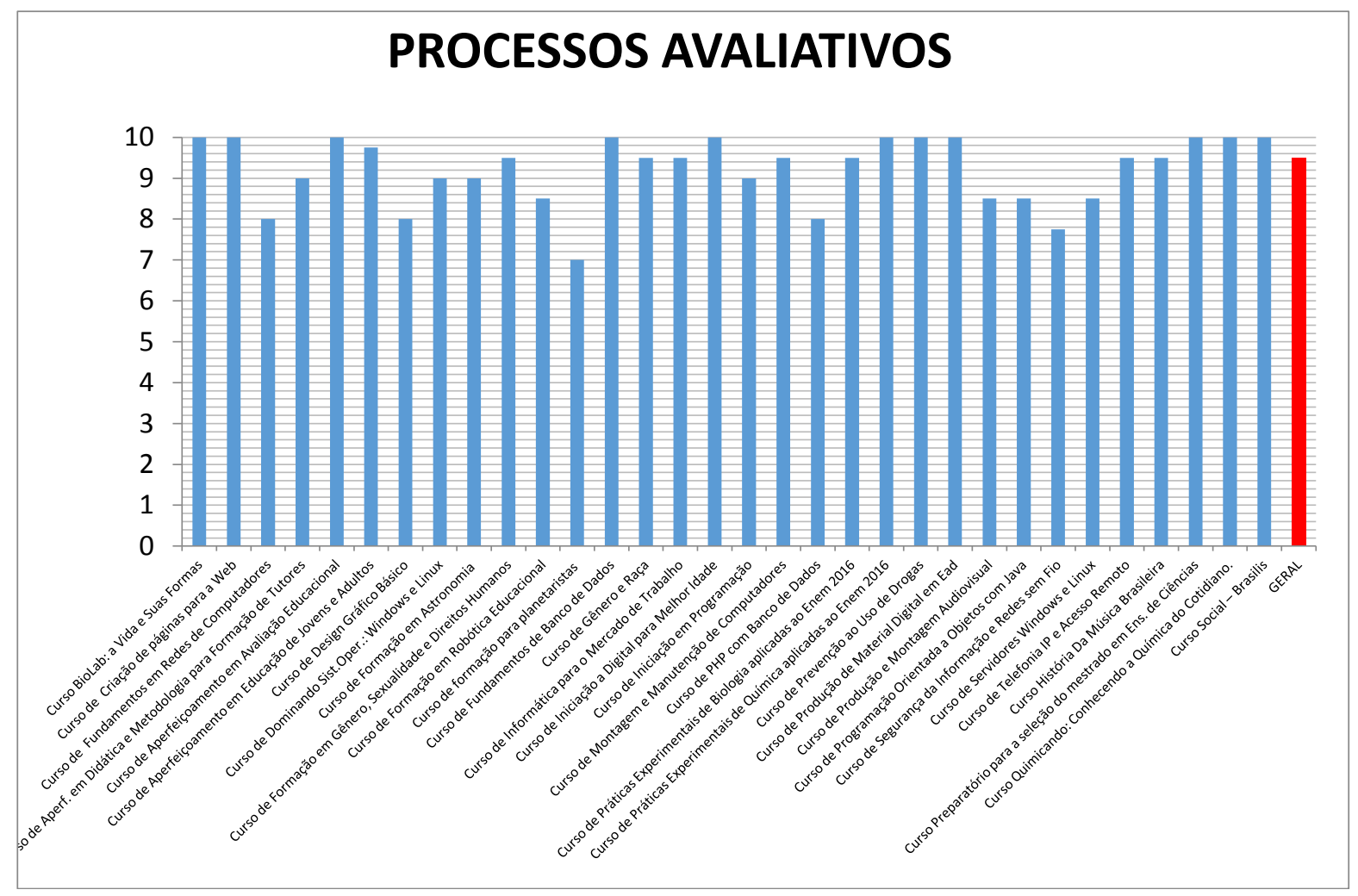

Fonte: Os autores.

Diferentemente do que preconiza a pesquisa científica, o processo avaliativo deve ser pautado em procedimentos teóricos sistematizados destinados à formulação de argumentos 
plausíveis a análises de um fenômeno e consequentemente discussões que acompanhem, obrigatoriamente, a tomada de decisões (VIANNA, 2000). Desta forma, espera-se que, com as possibilidades apresentadas neste trabalho, sejam possíveis transformações na forma de ver a avaliação dos cursos na EaD, propiciando uma reflexão crítica sobre sua qualidade.

\section{CONSIDERAÇÕES FINAIS}

Este trabalho apresenta algumas reflexões sobre a avaliação educacional, especificamente a avaliação baseada na metodologia SET. A metodologia SET visa dar aos alunos a possibilidade de avaliar seus professores, possibilitando intervenções pedagógicas por parte dos mesmos professores ou dos gestores do processo educacional.

Como pode ser observado na análise dos cinco indicadores obtidos, os cursos Fundamentos em Redes de Computadores, Design Gráfico Básico, Formação para Planetaristas e Produção e Montagem Audiovisual precisam de mudanças no sentido de suprir as carências apontadas pela sua avaliação. Destacam-se também os cursos Biolab, Criação de Páginas Web, Avaliação Educacional e Social Brasilis como exemplos a serem seguidos, com índice máximo em todos os indicadores.

Atravessamos um momento de expansão da EaD no Brasil, e a preocupação com a qualidade dos cursos nessa modalidade de ensino vem sendo recorrente. Para que essa qualidade possa ser investigada, faz-se necessária a avaliação dos cursos que estão sendo ofertados pelo país. Embora algumas instituições já tenham instrumentos que avaliem seus tutores, ressaltamos a necessidade da utilização de instrumentos robustos e consolidados com um bom suporte fatorial analítico, também chamado de suporte psicométrico. Para isso, apresenta-se o instrumento QEOn como possibilidade de avaliação dos tutores e dos cursos em EaD.

Como trabalhos futuros, destacamos a sistematização da aplicação do QEOn em uma IES para avaliar o impacto das ações pedagógicas para elevação dos indicadores de qualidade do ensino a distância. 


\section{REFERÊNCIAS}

ABBAD, G. S.; ZERBINI, T. E.; DE SOUZA, D. B. L. Panorama das pesquisas em educação a distância no Brasil. Estudos de Psicologia, v. 15, n. 3, p. 291-298, 2010.

ALVES, L. Educação a Distância: conceitos e história no Brasil e no mundo. Revista Brasileira de Aprendizagem Aberta e a Distância, v. 10, 2011.

APRESSOLA, N. A. Instrumento para avaliar as competências no trabalho de tutorial na modalidade ead. Dissertação de Mestrado, Universidade de São Paulo, 2010.

MARSH, H. W.; BAILEY, M. Multidimensional students' evaluations of teaching effectiveness: A profile analysis. The Journal of Higher Education, v. 64, n. 1, p. 1 - 18, 1993.

MARSH, H. W.; HOCEVAR, D. The multidimensionality of students' evaluations of teaching effectiveness: The generality of factor structures across academic discipline, instructor level, and course level. Teaching and Teacher Education, v. 7, n. 1, p. 9 - 18, 1991a.

MARSH, H. W.; HOCEVAR, D. Students' evaluations of teaching effectiveness: The stability of mean ratings of the same teachers over a 13-year period. Teaching and Teacher Education, v. 7, n. 4, p. $303-314,1991$ b.

MARSH, H. W.; ROCHE, L. A. Making students' evaluations of teaching effectiveness effective: The critical issues of validity, bias and utility. American Psychologist, v. 52, p. 1187 - 1197, 1997.

OZKAN, S.; KOSELER, R. Multi-dimensional students' evaluation of e-learning systems in the higher education context: An empirical investigation. Computers \& Education, v. 53, p. 1285 - 1295, 2009.

PEIXOTO, M. C. L. O debate sobre avaliação da educação superior: regulação ou democratização? In: Universidade: políticas, avaliação e trabalho docente, Cortez, 2004.

RIBEIRO, G. O; SILVA, T. E. V.; NUNES, A. O.; PINTO, F. A. P.; VASCONCELOS, F. H. L.. Avaliação da efetividade do ensino em um curso de formação continuada semipresencial. In: Anais do Workshop em Informática na Escola 2013, São Paulo, 2013, p. 369 - 379.

RICHARDSON, J. T. E. Instruments for obtaining student feedback: a review of the literature. Assessment and Evaluation in Higher Education, v. 30, n. 4, p. 387 - 415, 2005 b.

RICHARDSON, J. T. E. Students' perceptions of academic quality and approaches to studying in distance education. British Educational Research Journal, v. 31, n. 1, p. 7 - 27, 2005 a.

SEED. Relatório Técnico. Ministério da Educação, 2017. Disponível em :< http://portal.mec.gov.br/seed/arquivos/pdf/legislacao/refead1.pdf>. Acessado em 12 de janeiro de 2017.

SILVA, T. E. V. et al. QEOn Questionnaire for Assessing Experiences in Virtual Learning Environments. IEEE Latin America Transactions, v. 15, n. 6, p. 1196 - 1203, 2017.

SOBRINHO, J. D. Avaliação institucional: das perspectivas tecnológicas às políticas sociais. In: Avaliação da educação superior. Vozes, 2010.

SPOOREN, P.; MORTELMANS, D. Teacher professionalism and student evaluation of teaching: Will better teachers receive higher ratings and will better students give higher ratings. Educational Studies, v. 32, n. 2, p. $201-214,2006$.

TYLER, R. W. A Rationale for Program Evaluation. In: Evaluation Models, (Org.) TYLER, R. W. Kluwer-Nijhoff Publishing, 1993.

VIANNA, H. M. Avaliação Educacional: Teoria, Planejamento, Modelos. Ibrasa, 2000.

YUEH, H.P.; CHEN, T.L.; CHIU, L.A.; LEE, S.L.; WANG, A.B.. Student evaluation of teaching effectiveness of a nationwide innovative education program on image display technology. IEEE Transactions on Education, $v$. 55, n. 3, p. $365-369,2012$. 